\title{
BMJ Open Online survey comparing coping responses to SARS-CoV-2 by people with and without existing health conditions in the UK
}

\author{
Rachael Marie Hewitt (D) , ${ }^{1}$ Rachael Pattinson (D) , ${ }^{1}$ Rhian Daniel, ${ }^{2}$ \\ Judith Carrier (D) , ${ }^{1}$ Oliver Sanders, ${ }^{1}$ Christine Bundy ${ }^{1}$
}

To cite: Hewitt RM, Pattinson R, Daniel $\mathrm{R}$, et al. Online survey comparing coping responses to SARS-CoV-2 by people with and without existing health conditions in the UK. BMJ Open 2022;12:e051575. doi:10.1136/ bmjopen-2021-051575

- Prepublication history and additional supplemental material for this paper are available online. To view these files, please visit the journal online (http://dx.doi.org/10.1136/ bmjopen-2021-051575).

Received 23 March 2021 Accepted 03 December 2021

Check for updates

(C) Author(s) (or their employer(s)) 2022. Re-use permitted under CC BY-NC. No commercial re-use. See rights and permissions. Published by BMJ.

${ }^{1}$ School of Healthcare Sciences, Cardiff University, Cardiff, UK

${ }^{2}$ Division of Population Medicine, Cardiff University, Cardiff, UK

Correspondence to

Ms Rachael Marie Hewitt;

hewittr2@cardiff.ac.uk

\section{ABSTRACT}

Objectives To investigate the impact of SARS-CoV-2 on self-reported mood, coping and health behaviours of people living with existing health conditions in the UK to understand how to improve coping responses to the threat of SARS-CoV-2.

Design Quantitative design using a cross-sectional survey.

Setting Online survey in the UK.

Participants UK adults (18+ years) were eligible to participate. A total of 9110 people participated. Of these, 4377 (48\%) reported at least one existing health condition, $874(10 \%)$ reported having two or more existing conditions, and 715 (8\%) reported having an existing mental health condition.

\section{Primary and secondary outcome}

measures Multivariable linear regression and sequential multiple mediation analysis were used to estimate differences in average scores for active and avoidant coping response scores due to pre-existing health conditions, and to investigate the extent to which these differences are explained by differences in perceptions, beliefs, concerns and mood.

Results People with pre-existing physical $(+1.11$ higher; $95 \% \mathrm{Cl} 0.88$ to 1.34 ) and especially mental health conditions (3.06 higher; $95 \% \mathrm{Cl} 2.65$ to 3.48 ) reported poorer health and used more avoidant coping compared with healthy participants. Under some strong untestable assumptions, we estimate that experiencing low mood or concern related to SARS-CoV-2 mostly explained the relationship between existing health conditions and avoidant coping.

Conclusion Psychological support and interventions including behaviour change are required to mitigate the psychological burden of the SARS-CoV-2 pandemic and increase autonomy in people with and without pre-existing conditions during this highly uncertain time. Psychologists are well placed to support clinicians and people with existing health conditions to minimise the psychological impact of SARS-CoV-2, in order to alleviate the subsequent strain on healthcare services.

\section{INTRODUCTION}

On 23 March 2020, the UK government imposed a national movement restriction
Strengths and limitations of this study

- This is the first theory-led study in the UK to investigate cognitive, emotional and behavioural responses to the threat of SARS-CoV-2 among people who are vulnerable due to living with physical and mental health conditions.

- The rapid launch of the survey allowed data to be collected in real time but prohibited the validation of survey items.

- The majority of participants identified as being of white ethnic origin, limiting the generalisability of the findings to other ethnic groups, who we know to be disproportionately affected by SARS-CoV-2.

- The study was conducted by a multidisciplinary team with backgrounds in health psychology, statistics and nursing, and a member of the public.

(lockdown) to control the transmission of SARS-CoV-2. This caused major disruption to the economy and public systems (including disruption to health services), and signalled a serious potential threat to people's health and well-being. ${ }^{1}$ Responses to SARS-CoV-2 differed between countries and individuals differed in their reactions depending on the perception of this threat to health.

Perception of a health threat drives subsequent emotional and behavioural responses to it (Common Sense Model of Self-Regulation (CSM). ${ }^{2}$ Thus, what people think and feel about SARS-CoV-2 are likely to affect how they cope with it. We know that avoidant coping, including for example excessive alcohol intake or unhealthy, so-called 'comfort' eating, can adversely affect health outcomes. ${ }^{3}$ These health-threatening behaviours perpetuate the risk of serious non-communicable diseases, including cardiovascular and metabolic diseases and some cancers. ${ }^{4}$ Smoking $^{5}$ and being overweight or obese are associated with increased risk of hospitalisation, severe 
disease progression ${ }^{6}$ and death due to SARS-CoV-2. ${ }^{7}$ People living with existing health conditions (EHCs) are generally more susceptible to poor health and behavioural outcomes, ${ }^{8}$ which could worsen their condition(s) and further reduce their ability to cope with the threat of SARS-CoV-2. ${ }^{9}$

Higher rates of suicidal ideation, stress related to SARSCoV-2, anxiety and depression were evident among people with a mental EHC in the early stages of lockdown, ${ }^{10}$ and the presence of an EHC predicted worse mental health. ${ }^{11}$ This suggests that individuals with EHCs, mental illnesses especially, ${ }^{10}$ may be particularly vulnerable to poorer psychological outcomes related to SARS-CoV-2 and may require additional psychological support, ${ }^{12}{ }^{13}$ but these studies do not explain the psychological mechanisms underpinning health behaviours. A recent study showed that anxiety related to SARS-CoV-2 reduced general health and people's ability to cope with stress during the global pandemic, ${ }^{14}$ though most participants $(86 \%)$ reported no EHCs, limiting the generalisability of the findings.

Few studies have investigated how the threat of SARSCoV-2 impacts on people with EHCs. ${ }^{9}$ Umucu and Lee ${ }^{15}$ found that perceived stress related to SARS-CoV-2 was associated with maladaptive coping in people with chronic conditions and disabilities in the USA. However, their sample was small and coping responses between people with mental and physical EHCs were not compared. Comparing coping responses between groups and identifying the underlying psychological factors are essential for designing appropriate support for people with EHCs to cope with SARS-CoV-2.

We investigated the impact of SARS-CoV-2 on selfreported beliefs, mood and health behaviours of people in the UK living with one or more existing physical or mental EHCs in order to inform future interventions.

\section{METHODS \\ Design}

A cross-sectional online survey including free-text response boxes.

\section{Participants}

Adults aged 18 years and over living in the UK.

\section{Materials}

We developed an online survey comprised of four sections (online supplemental material 1, file 1): (1) participant demographics; (2) personal beliefs; (3) emotions and (4) behaviour towards the threat of SARS-CoV-2. Survey items in these sections were based on some, but not all, concepts from existing dominant theories and models of responses to health threats, including the $\mathrm{CSM}^{2}{ }^{2}$ the Transactional Model of Stress and Coping, ${ }^{16}$ the Health Belief Mode $^{17}$ and Protection Motivation Theory. ${ }^{18} \mathrm{~A}$ combination of complementary theories and models was favoured as each is particularly suited to examining either cognition, emotions or coping responses. ${ }^{19}$ See (online supplemental material 2, file 2) for a summary of survey items and related theoretical concepts.

Items were based on a 5-point Likert scale ranging from 'completely disagree' to 'completely agree'. A free-text box was included at the end of each section for participants to provide additional comments. To ensure data were captured in real time, the survey was not validated before use.

\section{Procedure}

The snowball sampling technique was adopted to recruit participants through existing author contacts via email and WhatsApp, as well as the websites and social media platforms (Twitter, Facebook, Instagram) of Cardiff University, HealthWise Wales (a research participant database) and Hywel Dda Health Board.

Survey completers were encouraged to share the survey. Informed consent was obtained prior to participants completing the survey. The survey was open from 8 April to 14 June 2020.

\section{Patient and public involvement}

A member of the public was involved in the analysis and interpretation of the free-text responses.

\section{Analysis}

We were primarily concerned with the extent to which EHCs affect coping and health behaviours, and the extent to which any effect is mediated through and moderated by different perceptions and emotions (online supplemental material 3, file 2). Age, gender, ethnic group and socioeconomic position (SEP) (proxied by educational qualifications and employment status) were considered as confounders. Variable definitions can be found in online supplemental material 4 , file $2 . \mathrm{X}^{2}$ tests were conducted to examine the relationship between EHCs and demographic variables.

Qualitative free-text responses were analysed and reported separately.

\section{Missing data}

The confounder and exposure data were completely observed. There were small amounts of item nonresponse in all other variables, ranging from $0.1 \%$ to $2 \%$, with a mean non-response proportion of $0.4 \%$ per item. However, due to the non-monotone pattern of nonresponse, $1494(16 \%)$ of the participants were missing at least one of the relevant items. A single stochastic regression imputation using chained equations ${ }^{20}$ was performed (online supplemental material 5, file 2).

\section{Overall effect: what is the effect of EHCs on coping and health behaviours?}

We fitted two multivariable linear regression analyses to the two coping outcomes (active and avoidance) with the exposure and confounders included as predictors. The exposure, EHC, was categorised into three groups: (1) no EHC; (2) at least one physical EHC but no mental EHC; and (3) a mental EHC, including those with both physical 
and mental EHCs. In a secondary analysis, to check if any differences identified in the first analysis were dominated by one or a small number of components, we repeated the above for each component of the active and avoidance coping scores separately (and not adjusting for each other). The estimated mean differences in the coping outcomes between EHC groups, adjusted for age, gender, ethnicity, education and employment, together with their 95\% CIs, are reported.

Mediation: to what extent is the effect of EHCs on coping and health behaviours mediated through threat perception and feelings?

A sequential multiple mediator analysis ${ }^{21}$ was performed to investigate the extent to which threat perception and emotions mediated the effect of EHCs on coping and health behaviours. The mediators were split into two groups (see online supplemental material 3, file 2) and an estimation-by-simulation approach was used to partition the estimated overall effect of EHCs on the coping outcomes first into (A) an indirect effect via some or all of the mediators and (B) a direct effect not via any of the mediators considered, and second to partition the indirect effect (A) into (A1) the indirect effect through the first set of mediators and (A2) the indirect effect through the second set of mediators, where any effect through both sets in sequence is included in (A1) (see online supplemental material 6 , file 2 for the full details, including the strong no unmeasured confounding assumptions on which this partitioning relies).

Effect modification: to what extent is the effect of EHCs on coping and health behaviours modified by threat perception and feelings? Effect modification was investigated directly from the multivariable linear models, with product terms added (see online supplemental material 7 , file 2).

\section{RESULTS}

There were 9110 respondents; 4377 (48\%) reported at least one EHC, of which 874 (10\%) reported having two or more EHCs, and 715 (8\%) reported having an existing mental health condition. Sample characteristics are presented in table 1 .

Participants without EHCs tended to be younger, female, from an ethnic group other than white, educated to college or university level, and in (full-time or parttime) employment or education. All of these findings are significant at $\mathrm{p}<0.001$ ( $\mathrm{X}^{2}$ test), though some differences were small (online supplemental material 8 , file 2).

After adjusting for confounding variables (age, gender, ethnic group, education and employment), having an EHC was estimated to decrease active coping scores but increase avoidance coping scores. Those with at least one physical EHC (but no mental EHC) had an active coping score on average 1.46 lower (95\% CI 1.11 to 1.80 ) and an avoidance coping score on average 1.11 higher $(95 \% \mathrm{CI}$ 0.88 to 1.34 ) than those without an EHC. The effect of
Table 1 Sample characteristics

\begin{tabular}{lc}
\hline Total & $\mathbf{n}(\%)$ \\
\hline
\end{tabular}

Survey

Cardiff University

$3016(33.1)$

HealthWise Wales

$6076(66.7)$

Hywel Dda

$18(0.2)$

Country

England

$52(0.8)$

Wales

$6139(99)$

Scotland

$9(0.1)$

Age (years)

18-30

807 (8.9)

$31-40$

$1111(12.2)$

41-50

$1322(14.5)$

$51-60$

$1898(20.8)$

61-70

$2472(27.1)$

$71-80$

$1337(14.7)$

$81+$

$150(1.6)$

Gender

Male

2791 (30.6)

Female

$6298(69.1)$

Other

$15(0.3)$

EHCs

$\begin{array}{lc}\text { Cardiovascular } & 791 \\ \text { Respiratory } & 1103 \\ \text { Diabetes } & 579 \\ \text { Cancer } & 235 \\ \text { Dementia } & 4 \\ \text { Mental illness } & 715 \\ \text { Pregnancy } & 64 \\ \text { Other } & 1931 \\ \text { Ethnicity } & \\ \text { White } & 8783(96.4) \\ \text { Black } & 34(0.4) \\ \text { Asian } & 101(1.1) \\ \text { Mixed/multiple ethnic groups } & 87(1) \\ \text { Other ethnic group } & 105(1.2) \\ \text { Highest qualification } & 1260(13.8) \\ \text { Usual high school qualifications in your } \\ \text { country at age 16 (eg, GCSE, O-level) }\end{array}$

Usual high school qualifications in your country at age 18 (eg, AS level, A-Level)

$828(9.1)$

A college or university diploma or degree 3945 (43.3)

A higher degree or professional qualification 2543 (27.9) (eg, a Doctorate or Masters level degree)

None of these qualifications

$318(3.5)$

Other

$140(1.5)$ 


\begin{tabular}{lr} 
Table 1 Continued & n (\%) \\
\hline \multicolumn{2}{l}{ Normally occupied } \\
$\quad$ Full-time & 3379 \\
Part-time & 1595 \\
Unemployed, seeking work & 67 \\
Unemployed, not seeking work & 281 \\
Full-time education & 340 \\
Part-time education & 102 \\
Volunteer & 436 \\
Homemaker & 256 \\
Retired & 3387
\end{tabular}

EHCs, existing health conditions.

having a mental EHC was greater than having a physical EHC. Those with a mental EHC (including those with both a mental and physical EHC) had an active coping score on average 3.16 lower (95\% CI 2.54 to 3.78 ) and an avoidance coping score on average 3.06 higher (95\% CI 2.65 to 3.48) than those without an EHC. The observed SDs of active and avoidance coping score variables in this sample (7.9 and 5.5, respectively) indicate the absolute magnitude of the significant effects were relatively small (table 2).

A secondary analysis of each component of active and avoidance coping scores, adjusted for the same confounders, showed that no single component was dominant in driving the results, and the results of some components in each score were in the opposite direction to the majority (online supplemental material 9, file 2).

A sequential multiple mediator analysis was performed to investigate the extent to which threat perception and feelings mediated the effect of EHCs on coping and health behaviours. Oonline supplemental material 3 (file 2) displays the mediators of interest.

Table 3 and online supplemental material 10 (file 2) show partitioning of active and avoidance coping outcomes into direct and indirect effects, and further into the indirect effects via the two groups of mediators separately; this is done for both the physical and mental EHC exposure comparisons. For the effect of one or more physical EHCs on active coping, almost no effects were mediated. Approximately 54\% (95\% CI: $43 \%$ to $65 \%$ ) of the effect of physical EHCs on avoidance coping was mediated via some or all of the mediators; $46 \%$ (95\% CI: $36 \%$ to $56 \%$ ) via concern and low mood; and $9 \%(95 \%$ CI: $1 \%$ to $17 \%$ ) via the first set (including any effects through both sets). For the effect of mental EHC on active coping, an estimated $23 \%$ (95\% CI: $14 \%$ to $32 \%$ ) of the effect was mediated by some or all of the mediators: $11 \%$ (95\% CI: $3 \%$ to $19 \%$ ) via the first set (including any effects through both sets) and $12 \%$ (95\% CI: $6 \%$ to $18 \%$ ) via concern and low mood only. An estimated $72 \%$ (95\% CI: $63 \%$ to $82 \%$ ) of the effect of mental EHC on avoidance coping was mediated via some or all of the mediators; $62 \%(95 \%$ CI: $53 \%$ to $71 \%$ ) estimated to be mediated via the second set only and the remaining $10 \%$ (95\% CI: $6 \%$ to $14 \%$ ) via the first set (including any effects through both sets).

Finally, we investigated the extent to which the effects of physical and mental EHCs on active and avoidance coping are modified by low mood, concern, primary threat perception, degrees of belief that scientists, politicians, healthcare workers and personal faith will overcome the threat, and the degree of fatalism ("what will be will be'). The effect of EHC on coping was remarkably stable across levels of all considered effect modifiers (see online supplemental material 11, file 2).

\section{DISCUSSION}

People living with one or more EHCs reported more avoidance than active coping behaviours in response to the threat of SARS-CoV-2 compared with participants with no EHCs. Avoidance coping was more common among people with mental EHCs than physical EHCs. Although based on strong 'no unmeasured confounding' assumptions, that demand caution in interpretation, our results suggest that the effects of the mental EHC exposure were mediated to a greater extent than the effects of the physical EHC exposure and that the effects on the avoidance coping outcome were mediated to a greater extent than the effects on the active coping outcome. Most of the mediation occurred via concern and low mood, though the effects of avoidance coping were mediated by primary threat perception, fatalism, personal faith and belief that scientists, politicians and healthcare workers will overcome the threat. Thus, people with EHCs were more likely to use avoidance coping behaviours due to feeling low or anxious.

In summary, people with EHCs, mental EHCs especially, in our large sample coped less effectively with the threat of SARS-CoV-2 during the imposed pandemic restrictions than people with no EHCs, indicating EHCs further inhibit people's ability to cope effectively with the threat and impact of SARS-CoV-2. We did not ask people to be specific which mental EHC they experienced, but it is safe to assume these included anxiety and depressive symptoms, which are the most common mental health conditions.

Individuals living with anxiety and depression symptoms are more likely to use health-threatening behaviours, including eating unhealthy food or drinking more alcohol than usual, as part of poor coping. Anxiety and depression have further increased as a reaction to the current and ongoing threat of SARS-CoV-2 and so the provision of dedicated psychological support incorporating behaviour change is urgently needed to address people's coping reactions to this health threat.

\section{What the present study adds}

The present study provides insight into the cognitive, emotional, and behavioural responses of people with 
Table 2 Results of linear regression models for active coping (left-hand side) and avoidance coping (right-hand side) on the categorical exposure EHC (none/at least one physical EHC but no mental EHC/mental EHC) and confounders

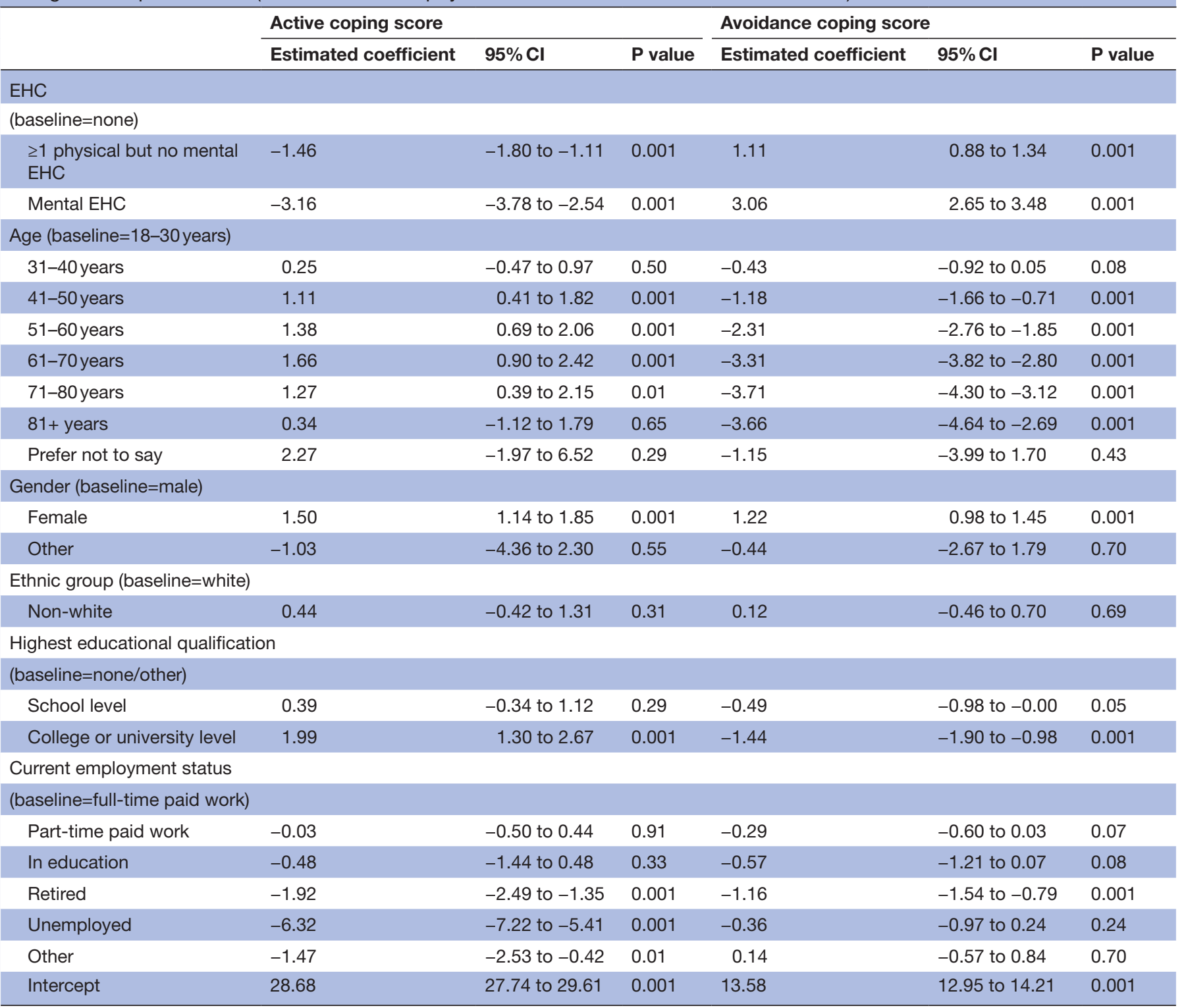

EHC, existing health condition.

EHCs towards the initial threat of SARS-CoV-2. It builds on the work of Umucu and Lee, ${ }^{15}$ demonstrating that avoidance coping was common in a much larger sample of adults with different physical and mental health conditions from across the UK. Furthermore, our study suggests that feeling low and anxious about SARS-CoV-2 partially explains the relationship between living with an EHC and avoidance coping. It highlights the need to improve how clinicians and patients manage mood, cope, and address behaviour change in current and future health threats.

\section{Strengths and limitations}

To our knowledge, this is the first theory-led study in the UK to investigate cognitive, emotional and behavioural responses to the threat of SARS-CoV-2 among people who are vulnerable due to living with physical and mental
EHCs. While the rapid launch of the survey prohibited the validation of survey items, we argue that the capture of this large dataset in real time strengthens rather than limits this study.

A major strength of this study is its large sample size; however, some limitations are apparent. First, our snowball sampling methods may have introduced withinsubject correlation and biased the findings towards those with access to social media. Second, the majority of participants were female $(69.1 \%)$ and there is evidence of sex differences in stress responses and coping strategies. ${ }^{22}$ Finally, despite targeted efforts to increase diversity, the majority of participants identified as being of white ethnic origin $(96.4 \%)$. Other ethnic groups are known to be disproportionately affected by SARS-CoV-2 due to 
Table 3 Results of sequential multiple mediator analyses for active (left-hand side) and avoidance coping (right-hand side)

\begin{tabular}{|c|c|c|c|c|c|c|}
\hline & \multicolumn{3}{|c|}{ Active coping score } & \multicolumn{3}{|c|}{ Avoidance coping score } \\
\hline & Estimated effect & $95 \% \mathrm{Cl}$ & $P$ value & Estimated effect & $95 \% \mathrm{Cl}$ & $P$ value \\
\hline \multicolumn{7}{|c|}{ Total effect of existing health condition (EHC) } \\
\hline \multicolumn{7}{|l|}{ (baseline=noEHC) } \\
\hline $\begin{array}{l}\geq 1 \text { physical but no } \\
\text { mental EHC }\end{array}$ & -1.44 & -1.81 to -1.08 & 0.001 & 1.13 & 0.92 to 1.33 & 0.001 \\
\hline Mental EHC & -3.51 & -3.87 to -2.42 & 0.001 & 3.08 & 2.62 to 3.54 & 0.001 \\
\hline \multicolumn{7}{|c|}{ Natural direct effect of EHC not mediated by $M_{1}$ nor $M_{2}$} \\
\hline \multicolumn{7}{|l|}{ (baseline=no EHC) } \\
\hline $\begin{array}{l}\text { At least one physical } \\
\text { EHC }\end{array}$ & -1.61 & -1.94 to -1.27 & 0.001 & 0.52 & 0.34 to 0.7 & 0.001 \\
\hline Mental EHC & -2.43 & -3.07 to -1.79 & 0.001 & 0.85 & 0.46 to 1.24 & 0.001 \\
\hline \multicolumn{7}{|c|}{$\begin{array}{l}\text { Natural indirect effect of EHC mediated by either } \mathrm{M}_{1} \text { or } \mathrm{M}_{2} \\
\text { or both }\end{array}$} \\
\hline \multicolumn{7}{|l|}{ (baseline=noEHC) } \\
\hline $\begin{array}{l}\text { At least one physical } \\
\text { EHC }\end{array}$ & 0.16 & -0.01 to 0.33 & 0.06 & 0.61 & 0.48 to 0.75 & 0.001 \\
\hline Mental EHC & -0.72 & -1.04 to -0.40 & 0.001 & 2.23 & 1.94 to 2.51 & 0.001 \\
\hline \multicolumn{7}{|c|}{$\begin{array}{l}\text { Natural indirect effect of EHC mediated by } M_{1} \text { (and possibly } \\
M_{2} \text { ) }\end{array}$} \\
\hline \multicolumn{7}{|l|}{ (baseline=noEHC) } \\
\hline $\begin{array}{l}\text { At least one physical } \\
\text { EHC }\end{array}$ & -0.01 & -0.15 to 0.13 & 0.88 & 0.10 & 0.01 to 0.19 & 0.03 \\
\hline Mental EHC & -0.35 & -0.60 to -0.09 & 0.01 & 0.31 & 0.19 to 0.44 & 0.001 \\
\hline \multicolumn{7}{|c|}{ Natural indirect effect of EHC mediated by $\mathrm{M}_{2}$ only } \\
\hline \multicolumn{7}{|c|}{ (baseline=noEHC) } \\
\hline $\begin{array}{l}\text { At least one physical } \\
\text { EHC }\end{array}$ & 0.17 & 0.09 to 0.26 & 0.001 & 0.51 & 0.40 to 0.63 & 0.001 \\
\hline Mental EHC & -0.37 & -0.57 to -0.18 & 0.001 & 1.91 & 1.67 to 2.16 & 0.001 \\
\hline
\end{tabular}

the higher prevalence of comorbidities and deprivation in these populations. ${ }^{23}$ Together, these issues limit the generalisability of the findings.

Finally, the causal interpretation of our estimates, both of the overall effects of EHC on coping outcomes, and of the extent to which these are mediated by threat perceptions, beliefs, concerns and low mood, all rely on strong untestable assumptions, mainly that there are no unmeasured common causes of any two or more of the sets of variables considered. For example, there could be other elements of SEP, beyond that captured by employment status and educational qualification, which confound the relationship between EHC and coping, and/or between the mediators and the outcomes or exposure. If these unmeasured components of low SEP increase the probability of having an EHC, decrease coping scores and increase low mood scores, for instance, then both the overall effect of EHCs and the extent to which it is mediated by low mood may be exaggerated.
Practical implications

The present study highlights that people with EHCs may require additional support to cope with future lockdowns and restrictions. Information alone is unlikely to initiate more appropriate coping and behaviour change. ${ }^{24}$ Health psychologists and behavioural scientists have expertise in evidence-based approaches to behaviour change as well as being well placed to advise government leaders and public health practitioners on appropriate approaches that help people with EHCs to cope effectively throughout pandemics.

The SARS-CoV-2 pandemic resulted in major changes to the delivery of healthcare services; the majority of routine consultations are now delivered remotely, allowing continuity of care. ${ }^{25}$ Increased demand has further increased the strain on the National Health Service (NHS), lengthening waiting times for mental health services. In addition, many people with EHCs have been unable or reluctant to attend medical appointments during the pandemic for fear of contracting SARS-CoV-2. The NHS will continue to be strained after the pandemic as it contends with this 
backlog. ${ }^{26}$ It is vital that clinicians acknowledge the cognitive, emotional, and behavioural factors facing people with EHC, who regularly access healthcare services, but greater financial investment must be provided to psychological services to support them. Addressing the psychological burden may not only help people with EHCs, but may reduce the long-term strain on the NHS.

\section{Future research}

We showed living with an EHC plus low mood and anxiety increases avoidance coping in response to SARSCoV-2. Future research should focus on health behaviour change interventions between the different conditions and specific patient groups. Understanding people's personal experiences of coping could inform the design and development of both population health and individual behaviour change interventions that are feasible to implement and acceptable to people with EHCs.

We remind clinicians of the need to routinely address well-being and coping with patients during medical consultations. Additional educational training may be necessary to enable clinicians to provide basic psychological support to people with EHCs throughout and beyond the SARS-CoV-2 pandemic.

\section{Conclusion}

People who live with a pre-existing physical or mental health condition are more likely to display avoidant coping behaviours in response to SARS-CoV-2, especially when experiencing low mood or anxiety. Given that these emotions are common among individuals with EHCs, increased funding and provision for dedicated psychological support in healthcare settings are urgently needed.

Twitter Rachael Marie Hewitt @rachaelmhewitt, Judith Carrier @carrierjak and Christine Bundy @BundyC

Acknowledgements Thank you to Cardiff University, HealthWise Wales and Hywel Dda Health Board for advertising the online survey. Thank you to the people who dedicated time and effort to completing the survey.

Contributors $\mathrm{RMH}$ - study design, data collection, analysis and interpretation, and manuscript drafting. RP-data analysis and interpretation and manuscript drafting. RD—data analysis and interpretation and manuscript drafting. JC—study conception and design, data interpretation and manuscript drafting. OS—data analysis and interpretation and manuscript drafting. $\mathrm{CB}$ - study concept and design, data collection, analysis and interpretation, manuscript drafting, and guarantor. All authors were given the opportunity to read and approve the final version of the manuscript for submission.

Funding The authors have not declared a specific grant for this research from any funding agency in the public, commercial or not-for-profit sectors.

Competing interests None declared.

Patient consent for publication Not required.

Ethics approval This study involves human participants and was approved by the School of Healthcare Sciences Research Ethics Committee, Cardiff University (REC723). Participants gave informed consent to participate in the study before taking part.

Provenance and peer review Not commissioned; externally peer reviewed.

Data availability statement Data are available upon reasonable request. The data that support the findings of this study are available from the corresponding author, $\mathrm{RMH}$, upon reasonable request.

Supplemental material This content has been supplied by the author(s). It has not been vetted by BMJ Publishing Group Limited (BMJ) and may not have been peer-reviewed. Any opinions or recommendations discussed are solely those of the author(s) and are not endorsed by BMJ. BMJ disclaims all liability and responsibility arising from any reliance placed on the content. Where the content includes any translated material, BMJ does not warrant the accuracy and reliability of the translations (including but not limited to local regulations, clinical guidelines, terminology, drug names and drug dosages), and is not responsible for any error and/or omissions arising from translation and adaptation or otherwise.

Open access This is an open access article distributed in accordance with the Creative Commons Attribution Non Commercial (CC BY-NC 4.0) license, which permits others to distribute, remix, adapt, build upon this work non-commercially, and license their derivative works on different terms, provided the original work is properly cited, appropriate credit is given, any changes made indicated, and the use is non-commercial. See: http://creativecommons.org/licenses/by-nc/4.0/.

\section{ORCID iDs}

Rachael Marie Hewitt http://orcid.org/0000-0002-3829-5604

Rachael Pattinson http://orcid.org/0000-0002-3145-3710

Judith Carrier http://orcid.org/0000-0002-2657-2280

\section{REFERENCES}

1 Varga TV, Bu F, Dissing AS, et al. Loneliness, worries, anxiety, and precautionary behaviours in response to the COVID-19 pandemic: a longitudinal analysis of 200,000 Western and Northern Europeans. Lancet Reg Health Eur 2021;2:100020.

2 Leventhal H, Nerenz DR, Steele DJ. Illness Representations and Coping with Health Threats. In: Baum A, Taylor SE, Singe JE, eds. Handbook of psychology and health (volume IV): social psychological aspects of health. London: Routledge, 1984.

3 Penley JA, Tomaka J, Wiebe JS. The association of coping to physical and psychological health outcomes: a meta-analytic review. $J$ Behav Med 2002;25:551-603.

4 Organisation WH. Non-Communicable diseases, 2018.

5 Zvolensky MJ, Garey L, Rogers AH, et al. Psychological, addictive, and health behavior implications of the COVID-19 pandemic. Behav Res Ther 2020;134:103715-15.

6 Chang Tu-Hsuan, Chou Chia-Ching, Chang Luan-Yin, et al. Effect of obesity and body mass index on coronavirus disease 2019 severity: a systematic review and meta-analysis. Obesity Reviews 2020;21:e13089-n/a

7 Popkin BM, Du S, Green WD, et al. Individuals with obesity and COVID-19: a global perspective on the epidemiology and biological relationships. Obesity Reviews 2020;21:e13128-n/a.

8 Anderson N, Ozakinci G. Effectiveness of psychological interventions to improve quality of life in people with long-term conditions: rapid systematic review of randomised controlled trials. BMC Psychol 2018;6:11.

9 Palmer K, Monaco A, Kivipelto M, et al. The potential longterm impact of the COVID-19 outbreak on patients with noncommunicable diseases in Europe: consequences for healthy ageing. Aging Clin Exp Res 2020;32:1189-94.

10 Fancourt D, Steptoe A, Bu F. Trajectories of anxiety and depressive symptoms during enforced isolation due to COVID-19 in England: a longitudinal observational study. Lancet Psychiatry 2021;8:141-9.

11 Shevlin M, McBride O, Murphy J, et al. Anxiety, depression, traumatic stress and COVID-19-related anxiety in the UK general population during the COVID-19 pandemic. BJPsych Open 2020;6:e125-e25.

12 Pedrosa AL, Bitencourt L, Fróes ACF, et al. Emotional, behavioral, and psychological impact of the COVID-19 pandemic. Front Psychol 2020;11:566212-12.

13 O'Connor DB, Aggleton JP, Chakrabarti B, et al. Research priorities for the COVID-19 pandemic and beyond: a call to action for psychological science. British Journal of Psychology 2020;111:603-29.

14 Yıldırım M, Akgül Ömer, Geçer E. The effect of COVID-19 anxiety on general health: the role of COVID-19 coping. Int J Ment Health Addict 2021:1-12.

15 Umucu E, Lee B. Examining the impact of COVID-19 on stress and coping strategies in individuals with disabilities and chronic conditions. Rehabil Psychol 2020;65:193-8.

16 Stress LRS. Appraisal, and coping. New York: New York: Springer, 1984.

17 Hochbaum G, Rosenstock I, Kegels S. Health belief model. Washington, DC : U.S.: Public Health Service, 1952.

18 Rogers RW. A protection motivation theory of fear appeals and attitude Change1. J Psychol 1975;91:93-114. 
19 Johnston M, Johnston DW. 8.04 - Assessment and Measurement Issues. In: Bellack AS, Hersen M, eds. Comprehensive clinical psychology. Oxford. Pergamon, 1998: 113-35.

20 White IR, Royston P, Wood AM. Multiple imputation using chained equations: issues and guidance for practice. Stat Med 2011;30:377-99.

21 VanderWeele TJ, Vansteelandt S. Mediation analysis with multiple mediators. Epidemiol Methods 2014;2:95-115.

22 Tamres LK, Janicki D, Helgeson VS. Sex differences in coping behavior: a meta-analytic review and an examination of relative coping. Personality and Social Psychology Review 2002;6:2-30.
23 Mishra V, Seyedzenouzi G, Almohtadi A, et al. Health inequalities during COVID-19 and their effects on morbidity and mortality. $J$ Healthc Leadersh 2021;13:19-26.

24 West R, Michie S, Rubin GJ, et al. Applying principles of behaviour change to reduce SARS-CoV-2 transmission. Nat Hum Behav 2020;4:451-9.

25 Ahmed S, Sanghvi K, Yeo D. Telemedicine takes centre stage during COVID-19 pandemic. BMJ Innovations 2020;6:252-4.

26 Association BM. The hidden impact of COVID-19 on patient care in the NHS in England, 2020. 